\title{
Interplay between IL-17 family members and angiogenic cytokines in subjects with systemic sclerosis
}

\author{
Ewa Robak ${ }^{1}$, Zofia Gerlicz-Kowalczuk ${ }^{2}$, Agata Liszewska ${ }^{1}$, Bozena Dziankowska-Bartkowiak ${ }^{1}$, \\ Anna Wozniacka ${ }^{1}$, Jaroslaw Bogaczewicz ${ }^{1,3}$
}

\begin{abstract}
${ }^{1}$ Department of Dermatology and Venereology, Medical University of Lodz, Poland ${ }^{2}$ Department of Dermatology, Pediatric Dermatology and Dermatological Oncology, Medical University of Lodz, Poland

${ }^{3}$ University of Economic and Human Sciences, Warsaw, Poland
\end{abstract}

Submitted: 9 February 2020; Accepted: 3 October 2020

Online publication: 21 March 2021

Arch Med Sci 2022

DOI: https://doi.org/10.5114/aoms/128102

Copyright $\odot 2022$ Termedia \& Banach

\begin{abstract}
Introduction: Systemic sclerosis (SSc) is a chronic, autoimmune connective tissue disease characterized by immune system activation, vasculopathy, and collagen accumulation. Despite progressive fibrosis of the vasculature, compensatory angiogenesis is impaired. The cause of the shift towards antiangiogenesis observed in SSc is unknown. The interleukin-17 (IL-17) cytokine family participates in the pathogenesis of SSc and angiogenesis.

Material and methods: Our study aimed to evaluate levels and find relationships between the levels of proangiogenic cytokines and cytokines from the IL-17 family in 42 SSc subjects and 20 healthy controls. Vascular endothelial growth factor (VEGF), placental growth factor (PIGF), hepatocyte growth factor (HGF), transforming growth factor $\beta 1$ (TGF- $\beta 1$ ), granulocyte/macrophage colony-stimulating factor (GM-CSF), IL-17A, IL-17B, IL-17E and IL-17F were quantified in the sera of all participants by ELISA sandwich kits.

Results: Significantly higher mean concentrations of PIGF compared to the control mean value $(19.3 \mathrm{pg} / \mathrm{ml}$ in the SSc group vs. $11.4 \mathrm{pg} / \mathrm{ml}$ in the control group; $p<0.001)$ and of HGF $(1931 \mathrm{pg} / \mathrm{ml}$ in the SSc group vs. $1483 \mathrm{pg} / \mathrm{ml}$ in controls; $p<0.05)$ were observed. Mean serum TGF- $\beta 1$ level was also significantly lower in the SSc group $(781 \mathrm{pg} / \mathrm{ml})$ than in controls $(35991 \mathrm{pg} / \mathrm{ml}$; $p<0.001)$. Among the IL-17 family, significantly higher mean concentrations of IL-17B $(67.0 \mathrm{pg} / \mathrm{ml}$ vs. $2.6 \mathrm{pg} / \mathrm{ml}$ in controls; $p<0.001), \mathrm{IL}-17 \mathrm{E}(8.0 \mathrm{pg} / \mathrm{ml}$ vs. $0.64 \mathrm{pg} / \mathrm{ml}$ in controls; $p<0.001)$ and IL-17F $(0.42 \mathrm{pg} / \mathrm{ml}$ vs. $0.0 \mathrm{pg} / \mathrm{ml}$ in controls; $p<0.01$ ) were detected. Serum concentrations of HGF and PIGF correlated with the concentrations of IL17A, IL-17B, and IL-17E.

Conclusions: Our findings indicate that selected cytokines from the IL-17 family participate in the pathogenesis of SSc and are responsible for the vascular abnormalities associated with this disorder.
\end{abstract}

Key words: vascular endothelial growth factor A, placenta growth factor, hepatocyte growth factor, angiogenesis inducing agents.

\section{Introduction}

Systemic sclerosis (SSc) is a chronic, autoimmune connective tissue disease whose key features include immune system activation, progressive vasculopathy and accumulation of collagen in the skin and viscera [1]. The early stages of the disease are characterized by immune system dysregulation and microvascular abnormalities; however, these are later

\author{
Corresponding author: \\ Prof. Ewa Robak \\ Department of Dermatology \\ and Venereology \\ Medical University of Lodz \\ 1 Haller's Square \\ 90-647 Lodz, Poland \\ Phone: +48 426867981 \\ Fax: +48 426884565 \\ E-mail: ewarobak@onet.eu
}


replaced by inflammation and fibrosis. Immunosuppressive therapy may prevent the progression of SSc. Worsening internal organ damage is also observed as a result of blood vessel occlusion caused by extracellular matrix deposition and fibrosis in the absence of compensatory angiogenesis. Although the agent responsible for displacing the equilibrium towards the antiangiogenic side in SSc remains unknown, it has been proposed that specific cytokines may inhibit new blood vessel formation. The authors define angiogenesis as the de novo formation of a primitive vascular network, and sprouting angiogenesis as the formation of new capillaries from existing vasculature coordinated by vascular endothelial growth factor (VEGF) $[2,3]$. However, VEGF overexpression may disrupt angiogenic pathways and stop angiogenesis from proceeding past the stage of vasculogenesis.

Increased levels of VEGF cannot make up for deficits in other angiogenic cytokines [4]. Another member of the VEGF family is placental growth factor (PIGF), increased levels of which might enhance the action of VEGF by recruiting monocytes and macrophages to inflammatory lesions via vascular endothelial growth factor receptor 1 (VEGFR1) and significantly enhancing pathological angiogenesis $[5,6]$. Hepatocyte growth factor (HGF) was proved to promote angiogenesis and the survival of neurons in a rat model [7]. It has also been shown that TGF- $\beta$ could induce angiogenesis via VEGF-mediated apoptosis and stimulate the transformation of lymphocytes into Th17 cells [8]. Zhao et al. discovered that the granulocyte/ macrophage colony-stimulating factor (GM-CSF) accelerated angiogenesis and wound healing by increasing the expression of VEGF [9].

Interleukin-17 (IL-17) has been found to influence the expression of VEGF, resulting in enhanced human retinal vascular endothelial cell (HREC) capillary tube formation [10]. It is speculated that its pro-angiogenic effect is mediated via VEGF-dependent and VEGF-independent pathways. Targeting the cytokine could therefore represent a potential therapeutic strategy against ocular neovascular diseases [11]; indeed, some reports indicate that the IL-17 cytokine family plays a key role in the pathogenesis of SSc and the process of angiogenesis [12-14]. Interestingly, the IL-17 family is known to display both angiogenic and antiangiogenic action: IL-17A stimulates new blood vessel formation, while IL-17B and IL-17F have antiangiogenic properties [15-19]. Recent findings indicate that IL-17 acts together with the complement system, cytoskeletal re-arrangement, and with VEGF and VEGF-related cytokines to exert its angiogenic effects. It predominantly targets endothelial, epithelial and stromal cells [11, 20, 21]. However, few studies have examined the potential of IL-17 to induce resistance against VEGF-blocking drugs, which are used for their anticancer and antiangiogenic properties $[22,23]$. There is currently a lack of information on the interactions between known proangiogenic factors and IL-17 family cytokines and their effects in neovascularization in SSc subjects.

Therefore the aim of our study was to evaluate the angiogenic activity of IL-17 family cytokines in patients with SSc. It examines the correlations between the levels of IL-17A, IL-17B, IL-17E and IL-17F and those of proangiogenic cytokines (VEGF, PIGF, HGF, TGF $\beta$, GM-CSF) in a group of 42 patients with SSC and another group of 20 healthy ageand gender-matched controls.

\section{Material and methods}

Forty-two patients with systemic sclerosis (SSc) were enrolled in the study: 39 women and three men. The diagnosis of SSc was made based on the 1980 criteria of the American College of Rheumatology, and the 2013 ACR/EULAR SSc Classification Criteria for SSc [24, 25]. Eleven subjects suffered from diffuse systemic sclerosis (dSSc) and 31 from limited systemic sclerosis (ISSc) in fulfillment of LeRoy's classification [26]. The control group $(n=20)$ consisted of healthy age-matched (17-70 years) and gender-matched individuals, who did not have any signs, symptoms or personal history of infectious, systemic or neoplastic disease. The study was approved by the Ethical Committee of the Medical University of Lodz, and informed consent was obtained from all participants.

\section{Clinical assessment}

Thorough clinical evaluation was performed on all the enrolled patients. The exact time of onset of Raynaud's phenomenon, thickening of the skin, duration of skin lesions and symptoms of internal organ damage were determined based on medical history. The area and severity of skin induration were evaluated according to Kahaleh et al. from 1986 (KTSS) [27]. Standard tests were carried out in all subjects: blood count, erythrocyte sedimentation rate, biochemical tests (serum creatinine, serum uric acid, AST, ALT) and urinalysis. Antinuclear antibody (ANA) levels were determined by indirect immunofluorescence (IIF) using the standard Sigma Diagnostics (USA) kit with HEp-2 tumor cells as the substrate. Precise identification was carried out using an agar gel immune-double-diffusion test, utilizing an extract of the veal thymus gland, which contains soluble nuclear antigens, as well as the Euroimmun Poland sp. z o.o. ELISA assay.

The involvement of individual organs was determined by esophageal transit scintigraphy, ECG, 24-hour Holter ECG monitoring, echocardiography, chest X-ray and high-resolution computed tomog- 
Table I. Clinical data of the patients with systemic sclerosis and its limited SSc and diffuse SSc forms

\begin{tabular}{|lcccc|}
\hline Characteristics & $\begin{array}{c}\text { Systemic sclerosis } \\
(n=42)\end{array}$ & $\begin{array}{c}\text { Limited SSc } \\
(n=31)\end{array}$ & $\begin{array}{c}\text { Diffuse SSc } \\
(n=11)\end{array}$ & $\begin{array}{c}\text { Limited SSc } \\
\text { vs. diffuse SSc }\end{array}$ \\
\hline Sex (female/male) & $39 / 3$ & $29 / 2$ & $10 / 1$ & $\mathrm{~ns}^{\star}$ \\
\hline Age [years] & $54.5 \pm 10.3$ & $54.4 \pm 10.7$ & $54.5 \pm 9.5$ & $\mathrm{~ns}^{\star *}$ \\
\hline Disease duration [years] & $9.5 \pm 6.3$ & $9.8 \pm 6.6$ & $8.54 \pm 5.7$ & $\mathrm{~ns}^{* *}$ \\
\hline Duration of Raynaud's phenomenon [years] & $13.7 \pm 7.8$ & $15.0 \pm 7.9$ & $10.0 \pm 6.3$ & $p=0.051^{\star *}$ \\
\hline Gastrointestinal manifestation, $n(\%)$ & $25(59)$ & $17(55)$ & $8(73)$ & $\mathrm{ns}^{\star}$ \\
\hline Cardiac involvement, $n(\%)$ & $29(69)$ & $19(61)$ & $10(91)$ & $\mathrm{ns}^{\star}$ \\
\hline Pulmonary fibrosis, $n(\%)$ & $18(43)$ & $13(42)$ & $5(45)$ & $\mathrm{ns}^{\star}$ \\
\hline Renal abnormalities, $n(\%)$ & $7(16)$ & $2(6)$ & $5(45)$ & $p<0.01^{*}$ \\
\hline Hematological involvement, $n(\%)$ & $10(24)$ & $7(22)$ & $3(27)$ & $\mathrm{ns}^{\star}$ \\
\hline Arthralgia, $n(\%)$ & $30(71)$ & $21(68)$ & $9(82)$ & $\mathrm{ns}^{*}$ \\
\hline
\end{tabular}

Results are shown as number and percent. Duration is represented in years as the mean \pm standard deviation.

${ }^{*}$ Fisher's exact test, ${ }^{* *}$ Mann-Whitney $U$ test, $n s-$ not significant, SSc - systemic sclerosis.

raphy $(\mathrm{HRCT})$. A five-year follow-up found the patients with ISSc to be taking medication to improve blood circulation: pentoxifylline, a calcium channel blocker (CCB) or an angiotensin-converting enzyme inhibitor (ACEI), or a combination with vitamin $\mathrm{E}$. They were also treated periodically with i.v. pentoxifylline or $10 \%$ Dextran 40 000. Some of the patients were also found to be either continuing the immunosuppressive therapy regimen that they had started earlier or one that had been modified according to clinical indications: corticosteroids such as $0.5 \mathrm{mg} / \mathrm{kg}$ BW (body weight) prednisone, or a cytotoxic agent such as $15 \mathrm{mg} /$ week methotrexate or cyclophosphamide, or a combination of them. All patients with SSc were taking vasodilators; some of them were also taking corticosteroids (15 patients: nine with ISSc, six with dSSc) and/or methotrexate (four patients: three with ISSc, one with dSSc) and/or cyclophosphamide (five patients: three with ISSc, two with dSSc). The clinical data of the patients are presented in Table I.

\section{Measurement of cytokine concentrations}

Blood samples were collected between 7 and 9 a.m. and kept at $4^{\circ} \mathrm{C}$ for one hour to allow a clot to form. They were then centrifuged for 60 seconds at $2000 \times$ g. Before the analysis, the obtained serum was split into aliquots and stored at $-80^{\circ} \mathrm{C}$. All clinical data were acquired immediately after the blood samples were taken. All medications, including immunosuppressive agents and steroid hormones, were withdrawn 24 hours before sampling.

VEGF, PIGF, HGF, transforming growth factor $\beta 1$ (TGF- $\beta 1$ ), GM-CSF, IL-17A, IL-17B, IL-17E and IL-F levels were quantified in the serum by ELISA sandwich kits in accordance with the producer's instructions (R\&D Systems Inc, Minneapolis, USA). Detection limits for the protocol were as follows: VEGF $=9.0$ $\mathrm{pg} / \mathrm{ml}, \mathrm{PIGF}=7.0 \mathrm{pg} / \mathrm{ml}, \mathrm{HGF}=24.1 \mathrm{pg} / \mathrm{ml}, \mathrm{TGF} \beta 1$ $=3.4 \mathrm{pg} / \mathrm{ml}, \mathrm{GM}-\mathrm{CSF}=3.0 \mathrm{pg} / \mathrm{ml}$, IL-17A $=0 \mathrm{pg} / \mathrm{ml}$, $\mathrm{IL}-17 \mathrm{~B}=2.5 \mathrm{pg} / \mathrm{ml}, \mathrm{IL}-17 \mathrm{E}=0 \mathrm{pg} / \mathrm{ml}, \mathrm{IL}-17 \mathrm{~F}=0 \mathrm{pg} / \mathrm{ml}$.
Intra-assay variation, determined by measuring standards and samples in duplicate, was found to be within the range given by the producer.

\section{Statistical analysis}

All analyses were performed using Statistica version 12 (StatSoft, Poland). As the distribution of serum levels of IL-17 was not normal (Shapiro-Wilk test), nonparametric tests were used to analyze the data: concentrations were compared with the Mann-Whitney $U$ test, categorical data with Fisher's exact test, and relationships were assessed with Spearman's rank correlation coefficient. Analysis of covariance (ANCOVA) was used to determine whether there were any significant differences between two or more independent parameters, such as the duration of Raynaud's phenomenon, age, and gender, in relation to a dependent variable. Concentrations were presented as mean \pm standard deviation, and median with lower $\left(25^{\text {th }}\right)$ and upper $\left(75^{\text {th }}\right)$ quartile $\left(25^{\text {th }}-75^{\text {th }}\right.$ centile). In all calculations, a $p$-value less than 0.05 was regarded as statistically significant.

\section{Results}

Serum concentrations of VEGF, PIGF, TGF- $\beta 1$, HGF, GM-CSF, IL-17A, IL-17B, IL-17E and IL-17F in patients with systemic sclerosis (SSC), diffuse SSC (dSSc) and limited SSc (ISSc), and in the control group are displayed in Table II.

\section{PIGF concentration in SSc patients and healthy controls}

The serum concentration of PIGF was significantly higher $(p<0.001)$ in the SSc group (mean value $19.3 \mathrm{pg} / \mathrm{ml}$ ), ISSc group (mean value $18.6 \mathrm{pg} / \mathrm{ml}$ ) and dSSc group (mean value $21.1 \mathrm{pg} / \mathrm{ml}$ ) compared to controls (mean value $11.4 \mathrm{pg} / \mathrm{ml}$ ). No differences in PIGF levels were found between the dSSc and ISSc groups. 
Table II. Serum concentrations of VEGF, PIGF, TGF- $\beta 1$, HGF, GM-CSF, IL-17A, IL-17B, IL-17E, and IL-17F in patients with systemic sclerosis, limited SSc, diffuse SSc and controls

\begin{tabular}{|c|c|c|c|c|c|}
\hline Variable & $\begin{array}{l}\text { Healthy control } \\
\text { group (c) } \\
n=20\end{array}$ & $\begin{array}{c}\text { Systemic } \\
\text { sclerosis (SSc) } \\
n=42\end{array}$ & $\begin{array}{l}\text { Limited SSc } \\
\quad(I S S c) \\
n=31\end{array}$ & $\begin{array}{l}\text { Diffuse SSc } \\
\quad(\mathrm{dSSc}) \\
n=11\end{array}$ & $\begin{array}{c}\text { Comparison with } \\
\text { Mann-Whitney } \\
U \text { test }\end{array}$ \\
\hline VEGF $[\mathrm{pg} / \mathrm{ml}]$ & $\begin{array}{c}427 \pm 209 \\
423 \\
(336-572)\end{array}$ & $\begin{array}{c}507.3 \pm 434.0 \\
474 \\
(191-595)\end{array}$ & $\begin{array}{c}463.7 \pm 462.4 \\
296 \\
(161-595)\end{array}$ & $\begin{array}{c}645 \pm 322 \\
550 \\
(496-938)\end{array}$ & $\begin{array}{l}\text { SSc vs. c: ns } \\
\text { ISSc vs. c: ns } \\
\text { dSSc vs. c: ns } \\
\text { ISSc vs. dSSc: ns }\end{array}$ \\
\hline $\mathrm{PIGF}[\mathrm{pg} / \mathrm{ml}]$ & $\begin{array}{c}11.4 \pm 2.5 \\
10.5 \\
(9.9-12.0)\end{array}$ & $\begin{array}{c}19.3 \pm 6.5 \\
17 \\
(14.9-22.5)\end{array}$ & $\begin{array}{c}18.6 \pm 6.1 \\
16.4 \\
(14.5-21.4\end{array}$ & $\begin{array}{c}21.1 \pm 7.5 \\
21.4 \\
(15.2-26.3)\end{array}$ & $\begin{array}{l}\text { SSc vs. c: } p<0.001 \\
\text { ISSc vs. c: } p<0.001 \\
\text { dSSc vs. c: } p<0.001 \\
\text { ISSc vs. dSSc: ns }\end{array}$ \\
\hline TGF- $\beta 1[\mathrm{pg} / \mathrm{ml}]$ & $\begin{array}{c}35991 \pm 9126 \\
3393 \\
(30666-38770)\end{array}$ & $\begin{array}{c}781.6 \pm 222.8 \\
794 \\
(693-897)\end{array}$ & $\begin{array}{c}748.5 \pm 239.1 \\
784 \\
(631-897)\end{array}$ & $\begin{array}{c}874.9 \pm 137.5 \\
807 \\
(792-996)\end{array}$ & $\begin{array}{l}\text { SSC vs. c: } p<0.001 \\
\text { ISSC vs. c: } p<0.001 \\
\text { dSSC vs. c: } p<0.001 \\
\text { ISSc vs. dSSc: ns }\end{array}$ \\
\hline $\mathrm{HGF}[\mathrm{pg} / \mathrm{ml}]$ & $\begin{array}{c}1483 \pm 495 \\
1482 \\
(1246-1742)\end{array}$ & $\begin{array}{c}1931 \pm 761 \\
1867 \\
(1419-2436)\end{array}$ & $\begin{array}{c}1845.3 \pm 726.5 \\
1738 \\
(1349-2436)\end{array}$ & $\begin{array}{c}2172 \pm 842 \\
1961 \\
(1675-2752)\end{array}$ & $\begin{array}{l}\text { SSc vs. c: } p<0.05 \\
\text { ISSc vs. } c: p<0.01 \\
\text { dSSc vs. c: } p<0.001 \\
\text { ISSc vs. dSSc: ns }\end{array}$ \\
\hline GMCSF [pg/ml] & $\begin{array}{c}0.39 \pm 0.38 \\
0.3 \\
(0.1-0.7)\end{array}$ & $\begin{array}{c}0.44 \pm 0.64 \\
0.3 \\
(0.0-0.8)\end{array}$ & $\begin{array}{c}0.32 \pm 0.61 \\
0.1\end{array}$ & $\begin{array}{c}0.7 \pm 0.6 \\
0.6 \\
(0.4-1.1)\end{array}$ & $\begin{array}{c}\text { SSc vs. c: } \mathrm{ns} \\
\text { ISSc vs. c: } \mathrm{ns} \\
\text { dSSC vs. c: } \mathrm{ns} \\
\text { ISSc vs. dSSc: } p<0.05\end{array}$ \\
\hline IL-17A [pg/ml] & $\begin{array}{c}0.63 \pm 2.0 \\
0.0 \\
(0.0-0.0)\end{array}$ & $\begin{array}{c}1.46 \pm 8.56 \\
0.0 \\
(0.0-0.0)\end{array}$ & $\begin{array}{c}0.16 \pm 0.64 \\
0.0 \\
(0.0-0.0)\end{array}$ & $\begin{array}{c}5.1 \pm 16.7 \\
0.0 \\
(0.0-0.0)\end{array}$ & $\begin{array}{l}\text { SSc vs. c: ns } \\
\text { ISSc vs. c: ns } \\
\text { dSSc vs. c: ns } \\
\text { ISSc vs. dSSc: ns }\end{array}$ \\
\hline IL-17B [pg/ml] & $\begin{array}{c}2.6 \pm 5.4 \\
0.0 \\
(0.0-2.45)\end{array}$ & $\begin{array}{c}67.0 \pm 71.6 \\
41.7 \\
(15.2-84.4)\end{array}$ & $\begin{array}{c}57.7 \pm 61.0 \\
28.7 \\
(14.7-78.4)\end{array}$ & $\begin{array}{c}93.2 \pm 94.1 \\
56.5 \\
(19.7-140.4)\end{array}$ & $\begin{array}{l}\text { SSc vs. c: } p<0.001 \\
\text { ISSc vs. c: } p<0.001 \\
\text { dSSc vs. c: } p<0.001 \\
\text { ISSc vs. dSSc: } \mathrm{ns}\end{array}$ \\
\hline IL-17E [pg/ml] & $\begin{array}{c}0.64 \pm 0.76 \\
0.25 \\
(0.0-1.3)\end{array}$ & $\begin{array}{c}8.0 \pm 9.1 \\
5.5 \\
(2.2-9.6)\end{array}$ & $\begin{array}{c}7.0 \pm 8.3 \\
4.7 \\
(2.0-8.5)\end{array}$ & $\begin{array}{c}10.7 \pm 11.1 \\
7.3 \\
(2.6-16.3)\end{array}$ & $\begin{array}{l}\text { SSc vs. c: } p<0.001 \\
\text { ISSc vs. c: } p<0.001 \\
\text { dSSc vs. c: } p<0.001 \\
\text { ISSc vs. dSSc: ns }\end{array}$ \\
\hline IL-17F [pg/ml] & $\begin{array}{c}0.0 \pm 0.0 \\
0.0 \\
(0.0-0.0)\end{array}$ & $\begin{array}{c}0.42 \pm 1.28 \\
(0.0-0.5)\end{array}$ & $\begin{array}{c}0.5 \pm 1.4 \\
0.0 \\
(0.0-0.5)\end{array}$ & $\begin{array}{c}0.0 \pm 0.0 \\
0.0 \\
(0.0-0.0)\end{array}$ & $\begin{array}{l}\text { SSc vs. c: } p<0.01 \\
\text { ISSc vs. c: } p<0.01 \\
\text { dSSc vs. c: } n s \\
\text { ISSc vs. dSSc: } n s\end{array}$ \\
\hline
\end{tabular}

Results are presented as mean \pm standard deviation, median, lower $\left(25^{\text {th }}\right)$ and upper $\left(75^{\text {th }}\right)$ quartile; ns - not significant, VEGF - vascular endothelial growth factor, PIGF - placental growth factor, TGF- $\beta 1$ - transforming growth factor $\beta 1$, HGF - hepatocyte growth factor, GM-CSF-granulocyte/macrophage colony-stimulating factor, IL-17 - interleukin-17.

When organ involvement was investigated separately, PIGF concentration was higher in ISSc patients with kidney involvement than in those without (respectively $25.5 \pm 11.7 \mathrm{pg} / \mathrm{ml}$ vs. $18.2 \pm 5.7 \mathrm{pg} / \mathrm{ml}$, $p<0.05)$. No other differences were found in PIGF level with regard to organ involvement. No relationship was found between gender and the serum concentration of measured cytokines in the SS, ISSc and dSSc groups.

\section{TGF- $\beta 1$ concentration in SSc patients and healthy controls}

Mean serum TGF- $\beta 1$ level was significantly lower $(p<0.001)$ in the SSc group $(781 \mathrm{pg} / \mathrm{ml})$, the
ISSc group $(748.5 \mathrm{pg} / \mathrm{ml}, p<0.001)$ and the dSSc group $(874.9 \mathrm{pg} / \mathrm{ml}, p<0.001)$ than in the controls (35991 pg/ml). No differences in TGF- $\beta 1$ levels were observed between the dSSc and ISSc groups.

\section{HGF concentration in SSc patients and healthy controls}

Mean serum HGF level was significantly higher in the SSc group (1931 pg/ml, $p<0.05)$, the ISSC group (1845.3 pg/ml, $p<0.01)$ and the dSSc group $(2172 \mathrm{pg} / \mathrm{ml}, p<0.001)$ than in controls (1483 pg/ $\mathrm{ml}$ ). No significant differences in HGF level compared to reference values were observed between dSSc and ISSc groups. 
In the ISSc group, both age and disease duration were correlated with HGF level (respectively $r=0.35$ and $r=0.39 ; p<0.05$ ) according to Spearman's correlation.

\section{GM-CSF concentration in SSc patients and healthy controls}

No significant differences in mean serum GM-CSF level were found between the SSc group $(0.44 \mathrm{pg} / \mathrm{ml})$, the $\mathrm{dSSc}$ group $(0.7 \mathrm{pg} / \mathrm{ml})$ or the $\mathrm{ISSC}$ group $(0.32 \mathrm{pg} / \mathrm{ml})$ and the controls $(0.39 \mathrm{pg} / \mathrm{ml})$. However, serum GM-CSF was significantly higher in the dSSc group $(p<0.05)$ than the ISSc group.

\section{VEGF concentrations in SSc patients and healthy controls}

No differences in mean serum VEGF concentrations were observed between the SSc group $(507.3 \mathrm{pg} / \mathrm{ml})$ and the reference group $(427 \mathrm{pg} / \mathrm{ml})$. No significant difference in mean VEGF levels were observed between controls and dSSc $(645 \mathrm{pg} / \mathrm{ml})$, controls and ISSc (463.7 pg/ml), or between dSSc and ISSC.

\section{IL-17B concentration in SSc patients and healthy controls}

Mean serum IL-17B level was higher in the SSc group $(67.0 \mathrm{pg} / \mathrm{ml}, p<0.001)$ than controls $(2.6 \mathrm{pg} / \mathrm{ml})$. Mean IL-17B levels were elevated in both the ISSc $(57.7 \mathrm{pg} / \mathrm{ml}, p<0.001)$ and $\mathrm{dSSC}$ (93.2 $\mathrm{pg} / \mathrm{ml}, p<0.001)$ cohorts compared to controls. No significant differences in IL-17B level were observed between the dSSC and ISSc groups.

\section{IL-17E concentration in SSc patients and healthy controls}

Mean serum IL-17E level was higher in the SSC (8.0 pg/ml, $p<0.001)$, ISSc $(7.0 \mathrm{pg} / \mathrm{ml}, p<0.001)$ and dSSc $(10.7 \mathrm{pg} / \mathrm{ml}, p<0.001)$ groups than in controls $(0.64 \mathrm{pg} / \mathrm{ml})$. No differences in IL-17E levels were observed between the dSSC and ISSc groups.

\section{IL-17F concentration in SSc patients and healthy controls}

Significantly higher mean serum concentrations of IL-17F were observed in the SSc group (0.42 pg/ml, $p<0.01)$ and the ISSc group (0.5 pg/ $\mathrm{ml}, p<0.01)$ compared to controls $(0.0 \mathrm{pg} / \mathrm{ml})$. No such difference was observed between the dSSc group $(0.0 \mathrm{pg} / \mathrm{ml})$ and controls, or between the dSSc and ISSc groups.

\section{IL-17A concentration in SSc patients and healthy controls}

No differences in mean serum IL-17A level were found between the SSc group $(1.46 \mathrm{pg} / \mathrm{ml})$ and controls $(0.63 \mathrm{pg} / \mathrm{ml})$. Similarly, no significant difference in IL-17A levels were found between diffuse (mean value $5.1 \mathrm{pg} / \mathrm{ml}$ ) and limited (mean value $0.16 \mathrm{pg} / \mathrm{ml}$ ) SSc groups and controls. In addition, no differences in IL-17A level were observed between the dSSc and ISSc groups.

A positive association was observed between VEGF and IL-17B levels $(r=0.48 ; p<0.05)$ and between VEGF and IL-17E levels $(r=0.54 ; p<0.05)$ in the SSc group.

The ANCOVA did not reveal other parameters such as age, duration of Raynaud's phenomenon and gender to be significant predictors of measured cytokines.

The significant correlations are presented in Figures $1 \mathrm{~A}-\mathrm{H}$.

Serum concentration of PIGF correlated with the concentrations of GM-CSF $(0.47 ; p<0.05)$ and IL-17A $(r=0.39 ; p<0.05)$.

No correlation was observed between the serum concentration of TGF- $\beta 1$ and of other investigated cytokines.

Serum HGF level correlated with concentrations of both IL-17B $(r=0.44 ; p<0.05)$ and IL-17E $(r=0.32, p<0.05)$.

A correlation was observed between serum concentrations of GM-CSF and IL-17A ( $r=0.5$; $p<0.05)$.

A positive correlation was found between the serum concentrations of IL-17B and IL-17E $(r=0.65 ; p<0.05)$.

No correlation was observed between the serum concentration of IL-17F and those of other investigated cytokines.

\section{Discussion}

Significantly higher concentrations of angiogenic cytokines (HGF, PIGF) were found in the study subjects with SSc, and their levels positively correlated with those of IL-17B, IL-17F, and IL-17E in serum, indicating their involvement in the pathogenesis of vascular abnormalities. Previous investigations from our group revealed that SSc patients present significantly higher IL-17B, IL-17F and IL-17E but not IL-17A levels [28]. Similarly, in the present study, IL-17A concentration was found to be lower than IL-17B, IL-17F and IL-17E and to not significantly differ within the SSc group; however, its level significantly correlated with PIGF and GM-CSF levels. The differences observed between the patient groups in the current and previous studies are due to a lack of serum samples, not patient selection: three patients did not provide sufficient serum to measure the concentrations of all cytokines.

The mean disease duration in the present study was 9.5 years, which indicates that the disease was in a chronic stage, i.e. clinical stabi- 

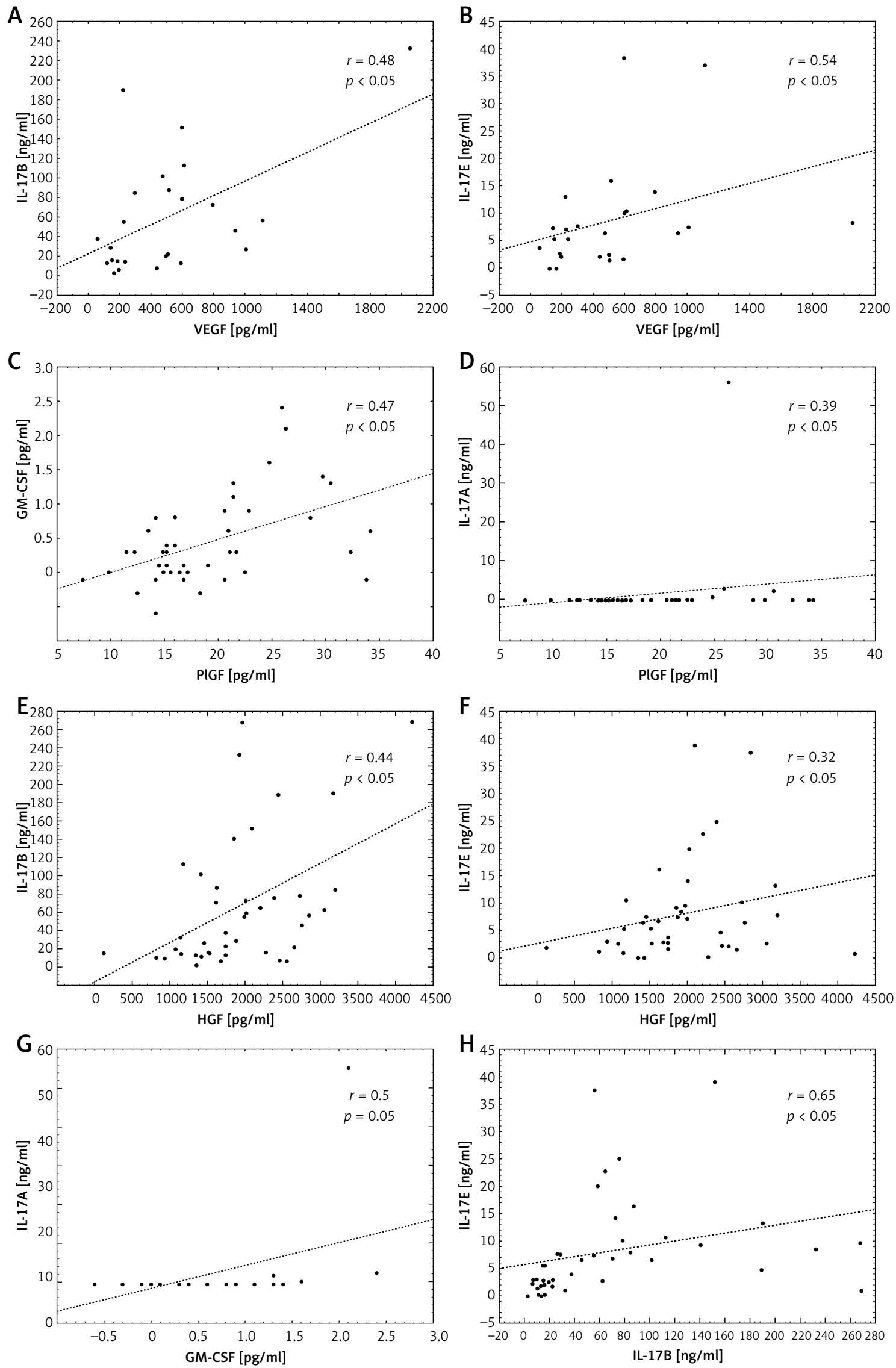

Figure 1. Correlations between measured cytokines in patients with systemic sclerosis. A - Correlation between serum concentrations of VEGF and IL-17B $(r=0.48 ; p<0.05)$. B - Correlation between VEGF and IL-17E $(r=0.54$; $p<0.05)$. C - Correlation between serum concentration of PIGF and GM-CSF $(r=0.47 ; p<0.05)$. D - Correlation between PIGF and IL-17A $(r=0.39 ; p<0.05)$. E - Correlation between serum concentration of HGF and IL-17B $(r=0.44 ; p<0.05)$. F - Correlation between HGF and IL-17 E $(r=0.32 ; p<0.05)$. G - Correlation between serum concentration of GM-CSF and IL-17A $(r=0.5 ; p<0.05)$. H - Correlation between serum concentration of IL-17B and IL-17E $(r=0.65 ; p<0.05)$ 
lization, predominated by fibrosis; this may have been responsible for the low levels of IL-17A found in the studied SSc subjects. A negative correlation has previously been reported between IL-17 levels and disease duration [29], and significantly increased production of IL-17 has been observed in early stage SSc [30]. Our present findings suggest the presence of higher levels of IL-17 at the onset of SSc, which subsequently decrease during the course of the disease. Earlier in vivo mouse studies indicate that IL-17 may play a role in the process of fibrosis: in a model of chronic lung hypersensitivity disease caused by Saccharopolyspora rectivirgula, IL-17A receptor-deficient mice were found to demonstrate decreased mononuclear infiltrates and lower collagen content in the lung compared with wild-type C57BL/6 mice [31]. Similarly, in a model of bleomycin-induced SSc in mice, the loss of IL-17A significantly ameliorated skin fibrosis [32]. However, the large majority of in vitro studies with human cells have failed to demonstrate any direct pro-fibrotic effect of IL-17A on fibroblasts. Brembilla et al. observed that in vitro Th17 cells increase inflammation while also suppressing collagen production in fibroblasts, likely protecting against fibrosis. This mechanism was to a certain extent determined by IL-17 [33]. It is important to continue with human research to establish whether IL-17 might play a therapeutic role in SSc, or whether its blockage would only facilitate the disease progression.

Placental growth factor is a member of the VEGF family. It has been shown to stimulate new blood vessel formation during conditions of hypoxia, tumor growth or wound repair, or when blood circulation is inadequate [34, 35]. PIGF elicits its biological effect through VEGFR1 [36]. PIGF has been observed to compete with VEGF for binding to VEGFR1 [34]. Clinical trials conducted in systemic sclerosis found that subjects with skin induration are more likely to demonstrate high concentrations of serum PIGF, and that this increase may be indicative of the formation of new digital ulcers. However, no association has been confirmed between PIGF level and pulmonary fibrosis in the course of SSc [37, 38].

The SSC group in the present study presented significantly higher PIGF levels than controls, which is consistent with previous reports. Our findings confirm those of Avouac et al. regarding the association between PIGF, skin involvement and digital ulcers [37]. There is a lack of data regarding correlations between PIGF and IL-17A in SSc subjects in the available literature. Investigators reported significantly lower expression of both cytokines within a group of subjects with preeclampsia, without significant correlations [39]. Our recent study on systemic lupus erythematosus patients showed significantly higher concentrations of both cytokines without any correlations between the two [40]. Therefore, it seems to be the first report of such a correlation occurring in a group of SSc patients.

GM-CSF has many functions. It promotes wound healing by stimulating angiogenesis, re-epithelization, and the recruitment of inflammatory cells $[41,42]$. GM-CSF has also been found to impede the deposition of type I collagen, but increase the production of other components of the extracellular matrix [43]. In addition, higher GM-CSF receptor expression was observed in SSc fibroblasts in vitro, suggesting that it may contribute to the pathogenesis of the disease [44]. Recently, an SSc group was found to demonstrate significantly higher GM-CSF expression than healthy controls; however, no variation was observed between ISSC and dSSc subgroups [45]. In the present study, although no difference in serum GM-CSF was found between SSc patients and controls, it was found to be significantly higher in dSSc $(p<0.05)$ than the ISSc group; this may account for the occurrence of rapidly progressive and more widespread cutaneous sclerosis in dSSc. IL-17 has also previously been found to potentiate GM-CSF release from human epithelial cells in vitro [46], and a positive feedback loop involving GM-CSF/IL-17A may exist, based on findings obtained in a mouse model of inflammatory dilated cardiomyopathy [47]. Similarly, in the present study, GM-CSF concentration correlated with IL-17A; however, further studies are needed in SSc subjects.

Similarly as for IL-17A, we did not find VEGF concentration significantly different in the SSC group; still it correlated with IL-17B and IL-17E, which confirms the possibility of correlations existing between the studied proteins. VEGF is a model example of an angiogenic cytokine. Recent reports reveal that it operates not only by stimulating angiogenesis (VEGF 165 isoform) but also by suppressing it (VEGF 165b-VEGF $A$ isoform) [48]. It has also been proven that in SSC patients, the balance between the two isoforms is biased in favor of antiangiogenic VEGF 165b. Over-expression of VEGF 165b was observed in the endothelial cells, fibroblasts and monocytes of SSc patients, constituting inflammatory infiltration surrounding the blood vessels [49]. Also, recent findings indicate increased production of VEGF 165 b by platelets in SSc patients, which further suggests their involvement in the abnormal angiogenesis associated with the disease [48].

Nevertheless, the agent responsible for displacing the equilibrium towards anti-angiogenesis in SSc subjects remains unknown; however, it does not lead to compensatory activation of angiogenesis - the repair process triggered in most medical 
conditions, including malignancies. Current investigations of cancer patients indicate that IL-17A triggers angiogenesis not only by stimulating endothelial cells but also by increasing VEGF release [50]. As neither cytokine was present in the SSc group, it can be assumed that angiogenesis had not been triggered.

Few, if any, reports regarding the effect of IL-17A on VEGF release in SSc subjects have been published so far. Zhou et al. report significantly elevated levels of IL-17A and VEGF mRNA expression in the affected skin of 10 SSc subjects; however, no reciprocal correlations were found between the two cytokines [51]. Previous studies have indicated that IL-17 has stimulating effects in this regard; together with IL- 6 and TGF- $\beta$, its activity contributes to increased fibroblast proliferation and endothelial cell activation [52]. In contrast, our present observation that VEGF concentration is positively correlated with increased IL-17B and IL-17E level suggests that an increase in IL-17B and IL-17E production may reverse the process of angiogenesis in SSc patients from a stimulating pathway to a suppressing one; however, this idea generally lacks support in the existing literature. Not only do our studies confirm the presence of increased concentrations of IL-17B and IL-17E, levels of which are related to those of VEGF and HGF, but also the relationship between them is statistically significant. Our findings emphasize the need for more detailed analysis of the signaling pathways in which these cytokines are engaged, particularly among patients with SSc.

The available literature suggests that IL-17E plays a more significant role in fibrosis than angiogenesis, and is known to have a strong impact on collagen production in lung fibroblasts [53]. Its expression has also been found to be increased in subjects with idiopathic pulmonary fibrosis, morphea and SSc $[54,55]$. Its widespread production by epithelial and endothelial cells, among others, may contribute to its wide distribution and contribution to many physiological and pathological processes related to the immunological response, inflammatory reaction and new blood vessel formation [56-60]. Similarly to IL-17E, IL-17B is manufactured by a range of cells: its mRNA has been identified in a wide range of cells and tissues, including the spinal cord, testis, stomach, small intestine, pancreas, prostate, ovary tissue and chondrocytes $[61,62]$. It has been found to suppress angiogenesis through its effect on the migration and growth of epithelial cells and tubule formation [15]. As a significant proportion of SSc patients in our study have associated interstitial lung disease, it is possible that this is a major factor responsible for the observed elevated levels of IL-17E. As indicated by our present findings, the concentrations of IL-17B and IL-17E correlate with one another; this relationship may be associated not only with their common origin from Th17 lymphocytes but possibly also with their function and their wide distribution. Monitoring the levels of the two cytokines in the course of SSc may be helpful in assessing disease severity.

Experimental studies indicate that IL-17F acts as an angiogenesis-inhibiting factor and that its activity is related to increased TGF- $\beta$ expression [63]. However, these findings are contradicted by those of our present test group, in which increased TGF- $\beta$ expression did not appear to have any influence on the antiangiogenic action of IL$17 \mathrm{~F}$. Although our findings do suggest a correlation between increased IL-17F level and disease progression, the concentration of TGF- $\beta$ in the SSc group was significantly below that observed in a healthy population, and no correlation was observed between the concentrations of the two cytokines.

Studies of patients with malignancies, immunologic diseases and diseases associated with extended fibrosis indicate that TGF- $\beta$ potentiates the production of VEGF $[64,65]$. However, as no significantly higher VEGF concentration was observed in our present investigation, it is likely that neither cytokine has any influence on the angiogenesis observed in our test group. In addition, no correlations were observed between TGF- $\beta$ and other IL-17 family interleukins. Therefore, the $a b$ normalities observed in the present study appear to be significantly interconnected with TGF- $\beta$-dependent signaling pathways. However, previous studies, focusing primarily on the antiangiogenic action of IL-17F in malignancies coupled with TGF- $\beta$ activity, emphasize the role of IL-17F in regulating angiogenesis and the expression of other cytokines in endothelial cells [16].

Trevor et al. suggest that the immunologic response involving activated TCD4 and monocytes may play a role in the inhibition of angiogenesis in malignant diseases, and that IL-17F could act to connect the two processes. However, few, if any observations have been published regarding this specific topic in SSc. The concentration of IL-17F in the sera of SSc patients remains unknown, as do IL-17B and IL-17E levels. Due to the lack of existing data regarding IL-17F in the pathogenesis of many diseases, it is hard to evaluate its contribution to the pathogenesis of abnormal angiogenesis in our test group. Nevertheless, our observation that it appears to be increased in the present study group prompts the need for further studies, especially in patients with SSC.

None of our patients used anti-VEGF, anti-IL, or anti-TNF therapy. However, some used glucocorticoids (GCs), methotrexate (MTX), or cyclophos- 
phamide $(\mathrm{CP})$, which are anti-inflammatory and immunosuppressive agents. Their activity could potentially affect the levels of the investigated IL-17 cytokines [66, 67], and insufficient data exist regarding their influence on angiogenesis. This is an important consideration as, due to the heterogeneous course of SSc, many different medications are used depending on the nature and degree of internal organ involvement: MTX is the drug of choice in skin and joint manifestations, whereas $C P$ is more effective in lung fibrosis and renal involvement. Although our patients' care was chosen according to expert recommendations [68], it is possible that these treatments could affect the findings in our SSc cohort.

In conclusion, our findings indicate that not only IL-17A but also other cytokines from the IL-17 family participate in the development of SSc. There is, hence, a need for clinical trials aimed at gaining a clearer understanding of its pathogenic influence, not only regarding angiogenesis but also on other pathways underlying the pathogenesis of SSc. The use of anti-IL-17 agents offers great hope as therapy for autoimmune diseases such as SSc and psoriasis or malignancies. One such agent, brodalumab, inhibits not only the activity of IL-17A, but also that of IL-17F and IL-17E. However, the lack of available information regarding the signaling pathways of the IL-17 cytokine family besides IL-17A further emphasizes the need for further investigations, before specific in vivo therapeutic targeting of IL-17B-E can be implemented [69].

\section{Acknowledgments}

This work was supported by the Medical University of Lodz, Poland, Grant no. 503/1-152-01/ 503-11-002.

The authors thank Edward Lowczowski from the Medical University of Lodz for editorial assistance.

\section{Conflict of interest}

The authors declare no conflict of interest.

\section{References}

1. Barsotti S, Mattaliano V, d'Ascanio A, et al. Systemic sclerosis chronic ulcers: preliminary results of treatment with allogenic skin grafting in a cohort of Italian patients. Int Wound J 2016; 13: 1050-1.

2. Sacilotto N, Chouliaras KM, Nikitenko LL, et al. MEF2 transcription factors are key regulators of sprouting angiogenesis. Genes Dev 2016; 30: 2297-309.

3. Vallée A, Guillevin R, Vallée JN. Vasculogenesis and angiogenesis initiation under normoxic conditions through Wnt/ $\beta$-catenin pathway in gliomas. Rev Neurosci 2018; 29: 71-91.

4. Carmeliet P. VEGF gene therapy: stimulating angiogenesis or angioma-genesis? Nat Med 2000; 6: 1102-3.
5. Park JE, Chen HH, Winer J, Houck KA, Ferrara N. Placenta growth factor. Potentiation of vascular endothelial growth factor bioactivity, in vitro and in vivo, and high affinity binding to Flt-1 but not to Flk-1/KDR. J Biol Chem 1994; 269: 25646-54.

6. Shibuya M. Vascular endothelial growth factor-dependent and -independent regulation of angiogenesis. BMB Rep 2008 ; 41: 278-86.

7. Kitamura K, Iwanami A, Nakamura M. Hepatocyte growth factor promotes endogenous repair and functional recovery after spinal cord injury. J Neurosci Res 2007; 85: 2332-42.

8. Ferrari G, Cook BD, Terushkin V, Pintucci G, Mignatti P. Transforming growth factor-beta 1 (TGF-beta1) induces angiogenesis through vascular endothelial growth factor (VEGF)-mediated apoptosis. J Cell Physiol 2009; 219: 449-58.

9. Zhao J, Chen L, Shu B. Granulocyte/macrophage colony-stimulating factor influences angiogenesis by regulating the coordinated expression of VEGF and the Ang/ Tie system. PLoS One 2014; 9: e92691.

10. Liu G, Wu H, Chen L. Effects of interleukin-17 on human retinal vascular endothelial cell capillary tube formation in vitro. Mol Med Rep 2017; 16: 865-72.

11. Li Y, Zhou Y. Interleukin-17: the role for pathological angiogenesis in ocular neovascular diseases. Tohoku J Exp Med 2019; 247: 87-98

12. Xing $X$, Yang J, Yang $X$. IL-17A induces endothelial inflammation in systemic sclerosis via the ERK signaling pathway. PLoS One 2013; 8: e85032.

13. Rodriguez-Reyna TS, Furuzawa-Carballeda J, Cabiedes J, et al. Th17 peripheral cells are increased in diffuse cutaneous systemic sclerosis compared with limited illness: a cross-sectional study. Rheumatol Int 2012; 32: 2653-60.

14. Radstake TR, van Bon L, Broen J, et al. The pronounced Th17 profile in systemic sclerosis (SSc) together with intracellular expression of TGFbeta and IFNgamma distinguishes SSc phenotypes. PLoS One 2009; 4: e5903.

15. Numasaki M, Fukushi J, Ono M. Interleukin-17 promotes angiogenesis and tumor growth. Blood 2003; 101: 2620-7.

16. Starnes T, Robertson MJ, Sledge G, et al. Cutting edge: IL-17F, a novel cytokine selectively expressed in activated $T$ cells and monocytes, regulates angiogenesis and endothelial cell cytokine production. J Immunol 2001; 167: 4137-40

17. Xie Y, Sheng W, Xiang J, Ye Z, Yang J. Interleukin-17F suppresses hepatocarcinoma cell growth via inhibition of tumor angiogenesis. Cancer Invest 2010; 28: 598-607.

18. Sanders AJ, Guo X, Mason MD, Jiang WG. IL-17B can impact on endothelial cellular traits linked to tumour angiogenesis. J Oncol 2010; 2010: 817375.

19. Tong Z, Yang XO, Yan $\mathrm{H}$, et al. A protective role by interleukin-17F in colon tumorigenesis. PLoS One 2012; 7: e34959.

20. Honorati MC, Neri S, Cattini L, Facchini, A. Interleukin-17, a regulator of angiogenic factor release by synovial fibroblasts. Osteoarthritis Cartilage 2006; 14: 345-52.

21. Lubberts E. IL-17/Th17 targeting: on the road to prevent chronic destructive arthritis? Cytokine 2008; 41: 84-91.

22. Chung AS, Wu X, Zhuang G, et al. An interleukin17-mediated paracrine network promotes tumor resistance to anti-angiogenic therapy. Nat Med 2013; 19: 1114-23.

23. Razia S, Noveiryc BB, Keshavarz-Fathia M, Rezae N. IL-17 and colorectal cancer: from carcinogenesis to treatment. Cytokine 2019; 116: 7-12. 
24. Preliminary criteria for the classification of systemic sclerosis (scleroderma). Subcommittee for scleroderma criteria of the American Rheumatism Association Diagnostic and Therapeutic Criteria Committee. Arthritis Rheum 1980; 23: 581-90.

25. van den Hoogen F, Khanna D, Fransen J, et al. 2013 classification criteria for systemic sclerosis: an American College of Rheumatology/European League against Rheumatism collaborative initiative. Arthritis Rheum 2013; 65: 2737-47.

26. LeRoy EC, Black C, Fleischmajer R, et al. Scleroderma (systemic sclerosis): classification, subsets and pathogenesis. J Rheumatol 1988; 15: 202-5.

27. Kahaleh MB, Suttany GL, Smith EA, Huffstutter JE, Loadholt CB, LeRoy EC. A modified scleroderma skin score method. Clin Exp Rheumatol 1986; 4: 367-9.

28. Robak E, Gerlicz Kowalczuk Z, Dziankowska-Bartkowiak B, Woźniacka A, Bogaczewicz J. Serum concentrations of IL-17A, IL-17B, IL-17E and IL-17F in patients with systemic sclerosis. Arch Med Sci 2019; 15: 706-12.

29. Olewicz-Gawlik A, Danczak-Pazdrowska A, Kuznar-Kaminska B, et al. Interleukin-17 and interleukin-23: importance in the pathogenesis of lung impairment in patients with systemic sclerosis. Int J Rheum Dis 2014; 17: 664-70.

30. Kurasawa K, Hirose K, Sano H, et al. Increased interleukin-17 production in patients with systemic sclerosis. Arthritis Rheum 2000; 43: 2455-63.

31. Simonian PL, Roark CL, Wehrmann F, et al. Th17-polarized immune response in a murine model of hypersensitivity pneumonitis and lung fibrosis. J Immunol 2009; 182: 657-65.

32. Okamoto Y, Hasegawa M, Matsushita T, et al. Potential roles of interleukin-17A in the development of skin fibrosis in mice. Arthritis Rheum 2012; 64: 3726-35.

33. Brembilla NC, Montanari E, Truchetet ME, Raschi E, Meroni P, Chizzolini C. Th17 cells favor inflammatory responses while inhibiting type I collagen deposition by dermal fibroblasts: differential effects in healthy and systemic sclerosis fibroblasts. Arthritis Res Ther 2013 15: R151.

34. Odorisio T, Cianfarani F, Failla CM, Zambruno G. The placenta growth factor in skin angiogenesis. J Dermatol Sci 2006; 41: 11-9.

35. Ludwicka A, Ohba T, Trojanowska M, et al. Elevated levels of platelet derived growth factor and transforming growth factor-beta 1 in bronchoalveolar lavage fluid from patients with scleroderma. J Rheumatol 1995; 22 1876-83.

36. Adini A, Kornaga T, Firoozbakht F, Benjamin LE. Placental growth factor is a survival factor for tumor endothelia cells and macrophages. Cancer Res 2002; 62: 2749-52.

37. Avouac J, Meune C, Ruiz B, et al. Angiogenic biomarkers predict the occurrence of digital ulcers in systemic sclerosis. Ann Rheum Dis 2012; 71: 394-9.

38. Hamaguchi Y, Hasegawa M, Tanaka C, et al. Elevated serum placenta growth factor (PIGF) levels in patients with systemic sclerosis: a possible role in the development of skin but not lung fibrosis. J Dermatol Sci 2010; 58: 229-31.

39. Mundim GJ, Paschoini MC, Araujo E Jr., Da Silva Costa F, Rodrigues V Jr. Assessment of angiogenesis modulators in pregnant women with pre-eclampsia: a case-control study. Arch Gynecol Obstet 2016; 293: 369-75.

40. Robak E, Kulczycka-Siennicka L, Gerlicz Z, Kierstan M, Korycka-Wolowiec A, Sysa-Jedrzejowska A. Correlations between concentrations of interleukin (IL)-17A, IL-17B and IL-17F, and endothelial cells and proangiogenic cytokines in systemic lupus erythematosus patients. Eur Cytokine Netw 2013; 24: 60-8.

41. Broughton SE, Dhagat U, Hercus TR, et al. The GM-CSF/ IL-3/IL-5 cytokine receptor family: from ligand recognition to initiation of signaling. Immunol Rev 2012; 250: 277-302.

42. Hu X, Sun H, Han C, Wang X, Yu W. Topically applied rhGM-CSF for the wound healing: a systematic review. Burns 2011; 37: 729-41.

43. Postiglione L, Ladogana P, Montagnani S, et al. Effect of granulocyte macrophage-colony stimulating factor on extracellular matrix deposition by dermal fibroblasts from patients with scleroderma. J Rheumatol 2005; 32: 656-64.

44. Postiglione L, Montagnani S, Riccio A, et al. Enhanced expression of the receptor for granulocyte macrophage colony stimulating factor on dermal fibroblasts from scleroderma patients. J Rheumatol 2002; 29: 94-101.

45. Zhu HL, DU Q, Chen WL, Zuo XX, Li QZ, Liu SJ. [Altered serum cytokine expression profile in systemic sclerosis and its regulatory mechanisms]. Beijing Da Xue Xue Bao Yi Xue Ban 2019; 51: 716-22.

46. Laan M, Prause O, Miyamoto $M$, et al. A role of GM-CSF in the accumulation of neutrophils in the airways caused by IL-17 and TNF-alpha. Eur Respir J 2003; 21: 387-93.

47. Wu L, Ong S, Talor MV, et al. Cardiac fibroblasts mediate IL-17A-driven inflammatory dilated cardiomyopathy. J Exp Med 2014; 211: 1449-64.

48. Hirigoyen D, Burgos PI, Mezzano V, et al. Inhibition of angiogenesis by platelets in systemic sclerosis patients. Arthritis Res Ther 2015; 17: 332.

49. Manetti M, Guiducci S, Romano E, et al. Overexpression of VEGF165b, an inhibitory splice variant of vascular-endothelial growth factor, leads to insufficient angiogenesis in patients with systemic sclerosis. Circ Res 2011; 109: e14-26.

50. Numasaki M, Fukushi J, Ono $M$, et al. Interleukin-17 promotes angiogenesis and tumor growth. Blood 2003; 101: 2620-7.

51. Zhou Y, Hou W, Xu K. The elevated expression of Th17-related cytokines and receptors is associated with skin lesion severity in early systemic sclerosis. Hum Immunol 2015; 76: 22-9.

52. Deleuran B, Abraham DJ. Possible implication of the effector CD4+ T-cell subpopulation TH17 in the pathogenesis of systemic scleroderma. Nat Clin Pract Rheumatol 2007; 3: 682-3.

53. Gregory LG, Jones CP, Walker SA, et al. IL-25 drives remodelling in allergic airways disease induced by house dust mite. Thorax 2013; 68: 82-90.

54. Hams E, Armstrong ME, Barlow JL, et al. IL25 and type 2 innate lymphoid cells induce pulmonary fibrosis. Proc Natl Acad Sci USA 2014; 111: 367-72.

55. Lonati PA, Brembilla NC, Montanari E, et al. High IL-17E and low IL-17C dermal expression identifies a fibrosis-specific motif common to morphea and systemic sclerosis. PLoS One 2014; 9: e105008.

56. Iwakura Y, Ishigame H, Saijo S, Nakae S. Functional specialization of interleukin-17 family members. Immunity 2011; 34: 149-62.

57. Song X, Qian Y. The activation and regulation of IL-17 receptor mediated signaling. Cytokine 2013; 62: 175-82.

58. Kang Z, Swaidani S, Yin W, et al. Epithelial cell-specific Act1 adaptor mediates interleukin-25-dependent helminth expulsion through expansion of Lin(-)c-Kit(+) innate cell population. Immunity 2012; 36: 821-33. 
59. Neill DR, Wong SH, Bellosi A, et al. Nuocytes represent a new innate effector leukocyte that mediates type-2 immunity. Nature 2010; 464: 1367-70.

60. Saenz SA, Siracusa MC, Perrigoue JG, et al. IL25 elicits a multipotent progenitor cell population that promotes $T(H) 2$ cytokine responses. Nature 2010; 464: 1362-6.

61. Shi Y, Ullrich SJ, Zhang J, et al. A novel cytokine receptor-ligand pair. Identification, molecular characterization, and in vivo immunomodulatory activity. J Biol Chem 2000; 275: 19167-76.

62. Li H, Chen J, Huang A, Stinson J. Cloning and characterization of IL-17B and IL-17C, two new members of the IL-17 cytokine family. Proc Natl Acad Sci USA 2000; 97 773-8.

63. Starnes T, Robertson MJ, Sledge G, et al. Cutting edge: IL-17F, a novel cytokine selectively expressed in activated $T$ cells and monocytes, regulates angiogenesis and endothelial cell cytokine production. J Immunol 2001; 167: 4137.

64. Prud'homme JG. Pathobiology of transforming growth factor $b$ in cancer, fibrosis and immunologic disease, and therapeutic considerations. Lab Invest 2007; 87: 1077-91.

65. Shao S, Fang H, Duan L, et al. Lysyl hydroxylase 3 in creases collagen deposition and promotes pulmonary fibrosis by activating TGF $\beta 1 / \mathrm{Smad} 3$ and $\mathrm{Wnt} / \beta$-catenin pathways. Arch Med Sci 2019; 16: 436-45.

66. Wang A, Wang F, Yin Y, Zhang M, Chen P. Dexamethasone reduces serum level of IL-17 in Bleomycin-A5-induced rats model of pulmonary fibrosis. Artif Cells Nanomed Biotechnol 2018; 46: 783-7.

67. Li Y, Jiang L, Zhang S, et al. Methotrexate attenuates the Th17/IL-17 levels in peripheral blood mononuclear cells from healthy individuals and RA patients. Rheumatol Int 2012; 32: 2415-22.

68. Krasowska D, Rudnicka L, Dańczak-Pazdrowska A, et al. Systemic sclerosis - diagnostic and therapeutic recommendations of the Polish Dermatological Society. Part 2: treatment. Dermatol Rev/Przegl Dermatol 2017; 104 583-96.

69. Speeckaert R, Lambert J, Grine L, Van Gele M, De Schepper S, van Geel N. The many faces of IL-17 in inflammatory skin diseases. Br J Dermatol 2016; 175: 892-901. 